\title{
Producción de energía alternativa a partir de biogestores, utilizando el estiercol producido por el ganado,Quito, Ecuador, Diciembre 2008
}

\section{Autores:}

Ing. José Luís Cedeño Zambrano

Ing. Silvia Dávila

Víctor Valencia 


\section{Resumen}

En el país existe escasez de energía y tendido eléctrico en sectores rurales y en donde los costos son demasiado elevados para su funcionamiento debido a una baja población lo que lleva a que los gobiernos locales le den poca importancia a estos sectores en lo referente a necesidades básicas como energía eléctrica, agua potable, medicina y salubridad. Adicionalmente los estiércoles ganaderos son generadores de contaminación para las fuentes de agua. Una alternativa para la solución de estos problemas es la utilización de un biodigestores de flujo continuo, el cual producirá gas para la cocina y energía eléctrica para uso en la ganadería y en la casa de los agricultores, reduciendo así la contaminación. La digestión anaeróbica es considerada una herramienta efectiva del manejo de desechos orgánicos ylaproducción de metano como fuente de energía renovable. Sin embargo, su diseminación ha sido limitada por los altos costos de instalación de plantas de biogás convencionales. Una planta de biogás de polietileno es una alternativa para la producción de biogás a bajo costo ( $\$ 300)$. Este estudio estima los beneficios directos y funcionales que pueden derivarse de la instalación de un biodigestor de 12 metros de largo para lo cual se evaluaron los tratamientos: Estiércol bovino (T1), Estiércol porcino ( $\mathrm{T} 2$ ), y Estiércol mixto ( $\mathrm{T} 3$ ). Evaluándose los parámetros de producción de biogás, valor contaminante, mineralógico del efluente y sus usos en la producción de energía para cocción y como fuente de combustible de un generador de electricidad. La producción de biogás fue ligeramente superior en el estiércol porcino, no existiendo diferencias significativas entre los tratamientos. En el caso del efluente del biodigestor este cumple con los parámetros de la legislación ecuatoriana de efluentes para alcantarillas lo cual garantiza que este sistema anaeróbico funciona en la descontaminación de aguas de la ganadería. El funcionamiento adecuado del motor generador de electricidad ( $5000 \mathrm{~W})$ se dió con el gas comercial butano abasteciendo a toda la necesidad de la finca 25 amperios, mientras que con el biogás su funcionamiento fue insuficiente, solo funcionando para el consumo de 2,4 amperios. Los biodigestores ayudan en sistemas de producción ganaderos, descontaminan sus aguas residuales, generan gas para producción de energía y producen un abono para los cultivos o pasturas. Es recomendable realizar futuras investigaciones para mejorar la calidad del biogás para generación de energía eléctrica, mejorar la eficiencia de producción y búsqueda de otros usos en la producción animal tropical.

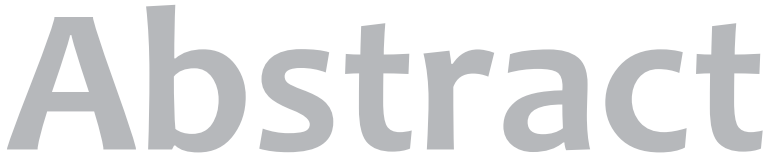

In the country, there is energy shortage and not enough wire electric netting in rural sectors, where the costs are too high for its operation due to a low population which takes to that the local governments give little importance to these sectors regarding basic necessities as electric power, drinkable water, medicine and health.

In addition, the cattle dung increases pollution for the sources of water. A choice for the solution of this problem is the use of a biodigestible of continuous flow, which will produce gas for the kitchen and electric power for use in the cattle rising and in the house of the farmers, reducing this way the contamination. The anaerobic digestion is considered an effective tool of the handling of organic waste and the methane production like source of renewable energy. However, their dissemination has been limited because of the high costs of installation of plants of conventional bio-gas. A plant of polyethylene bio-gas is an alternative for the bio-gas production at low cost (\$300). This study considers the direct and functional benefits that can be derived of the installation of a bio-digester of 12 meters long in order to evaluate the treatments: Bovine dung ( $\mathrm{T} 1)$, pigs dung ( $\mathrm{T} 2)$, and mixed dung (T3). Thus, the parameters of bio- gas production, polluting value, mineralogy and their uses in the energy production for cook- 
ing and source of fuel of an electricity generator were evaluated. The bio-gas production was lightly superior in the pigs dung, not existing significant differences among the treatments. In the case of the bio-digester' fluid, it carries out the parameters of the Ecuadorian legislation of fluid for sewers which guarantees that this anaerobic system works in the decontamination of waters of the cattle raising. The appropriate operation of the generating motor of electricity (5000 W) was given with the gas commercial butane supplying to the whole necessity of the property 25 amperes, while with the bio-gas their operation was not enough, and it just works for the consumption of 2,4 amperes. The bio digesters helps in cattle production systems, they decontaminate their residual waters, generate gas for energy production and they produce a fertilizer for the crops. It is advisable to carry out future investigations to improve the quality of the bio gas for electric power generation, to improve the production efficiency and search of other uses in the tropical animal production.

\section{Introducción}

Según los datos del Tercer Censo Nacional Agropecuario, existen 4.486.020 de cabezas de ganado bovino y 1.527.114 cabezas de ganado porcino lo cual genera diariamente gran cantidad de estiércol que va a dar a pastizales, quebradas, ríos entre otros. Se estima que la producción de estiércol por cada $100 \mathrm{~kg}$ de peso vivo es de $6 \mathrm{~kg}$ para bovinos y de $4 \mathrm{~kg}$ para porcinos de estiércol en base húmeda (CIPAV, Centro para la Investigación en Sistemas Sostenibles de Producción Agropecuaria, 2000)

La FAO en varias de sus publicaciones cita a la agricultura como causa de aproximadamente un tercio de las emisiones de gases de efecto invernadero. Las actividades como la labranza de la tierra y el cultivo itinerante ("tala y quema") para la expansión de la agricultura provocan emisiones de $\mathrm{CO}_{2}$ en el aire. El 40 por ciento del metano de origen humano procede de la descomposición de la materia orgánica en los arrozales inundados. Aproximadamente el 25 por ciento de las emisiones mundiales de metano tiene su origen en la ganadería. Además, la agricultura produce el 80 por ciento de las emisiones de óxido nitroso de origen humano mediante la descomposición de los fertilizantes, del abono y la orina del ganado. No obstante, las emisiones de gases de efecto invernadero procedentes de la agricultura pueden reducirse en buena medida y es mucho lo que se puede hacer para paliar sus efectos en la producción y en los medios de subsistencia de los agricultores, sobre todo en los países en desarrollo. Las proyecciones sugieren que para el año 2030, las emisiones de amoníaco y metano procedentes del sector pecuario de los países en desarrollo será al menos un 60 por ciento mayor que en la actualidad.

El sector ganadero genera más gases de efecto invernadero - el 18 por ciento, medidos en su equivalente en dióxido de carbono (CO2) - que el sector del transporte. Una de las estrategias para mitigar esta situación según la FAO es una alimentación del ganado más acertada y un mejor manejo de su estiércol. Además, los gobiernos nacionales pueden contribuir notablemente a imponer el cumplimiento de políticas de explotación de la tierra que desalienten la expansión de las prácticas de tala y quema y la ganadería extensiva (en vez de la intensiva), así como el aumento de las oportunidades de empleo rural.

En la actualidad uno de los principales problemas que se tienen en toda explotación ganadera es el manejo que se le pueda dar a la gran cantidad de desechos generados en forma de excretas, lo cual tradicionalmente se ha limitado al simple lavado de los corrales utilizando grandes cantidades de agua que finalmente son depositados en fuentes de agua, causando su contaminación.

Estos desechos son altamente contaminantes debido a que contienen materia orgánica, microorganismos y nutrimentos, lo que conlleva entre otros a la disminución del oxígeno disponible y el aumento de contenido de amonio en el agua, lo que provoca la muerte de la vida acuática y además, amenaza la vida terrestre al ser consumida el agua por personas, animales y plantas. (Cedeño, 2005) 
En el país existe una escasez de energía y tendido eléctrico en sectores rurales donde los costos son demasiado elevados para su funcionamiento. Adicionalmente los estiércoles ganaderos son generadores de contaminación para las fuentes de agua. La alternativa para estos problemas es la utilización de un biodigestor de flujo continuo que producirá gas para la cocina, y energía eléctrica para los usos en la ganadería y en la casa del agricultor, reduciendo así la contaminación al ecosistema.

Los biodigestores son importantes ya que permiten transformar desechos sólidos provenientes de la actividad pecuaria en biogás y fertilizantes y así reducir la contaminación de las fuentes de agua y reducir el efecto invernadero al liberarse menos metano a la atmósfera. Con el objetivo de tratar residuos orgánicos, reducir la contaminación ambiental y el riesgo de transmisión de enfermedades se propuso introducir las excretas animales dentro de un biodigestor construido con una bolsa tubular de polietileno, alojada en una fosa excavada sobre el suelo. Este tipo de biodigestor permite producir, almacenar y utilizar el biogás y el abono orgánico (biol), obtenidos como producto de la fermentación de la materia orgánica contenida en las excretas. El biogás producido elimina la necesidad de utilizar leña para la cocción de los alimentos en el medio rural del cinturón tropical del mundo y la posibilidad de generar suficiente energía eléctrica necesaria para la vivienda campesina.

Las familias campesinas pueden mejorar su bienestar, pues ya no tiene que emplear tiempo para recolectar leña y la cocción no produce humo nocivo para la salud de las personas que cocinan los alimentos que consumen las familias rurales. Se han cuantificado los beneficios de la siguiente manera: Un biodigestor de polietileno de tamaño familiar, que funciona diariamente con 20 kilogramos de excretas frescas (lo cual es producido por 1 vaca ó 2 caballos ó por 5 cerdas de cría confinadas permanentemente y 100 litros de agua limpia (puede ser agua lluvia), tiene la capacidad de producir biogás para generar 7 horas de llama por día y el costo de instalación es el equiva- lente de 300 dólares, en cualquier país tropical.

El biogás permite sustituir el gas propano (derivado del petróleo) que tiene que ser comprado en el mercado (US \$ 2 el cilindro de 20 libras) y el abono orgánico (efluente del biodigestor) permite sustituir el abono químico ( $\mathrm{N}, \mathrm{P}, \mathrm{K})$. El abono orgánico y el biogás producidos durante seis (6) meses permiten cubrir todos los costos de la inversión hecha para instalar el biodigestor. La vida útil de la bolsa plástica puede ser hasta de diez (10) años. La eliminación del uso de leña para la cocción de los alimentos reduce la deforestación.

La utilización del abono orgánico producido por el biodigestor permite incrementar los rendimientos en todo tipo de cultivos y acuicultura; produciendo alimentos nutritivos y variados para autoconsumo y excedentes para la venta, permitiendo así una mejor nutrición, aumento de los ingresos y bienestar de las familias campesinas. (Botero y Preston, 1997)

El modelo original de este tipo de biodigestor se creó en Taiwán (Pound et al. 1981). En 1986 se hicieron adaptaciones a los accesorios disponibles en el mercado colombiano, en la Fundación Centro para la Investigación en Sistemas Sostenibles de Producción Agropecuaria - CIPAV (Botero y Preston, 1987) y posteriormente en la Universidad EARTH en Costa Rica, América Central (Botero, Aguilar y Preston, 1998).

En Colombia se inició su instalación y utilización en 1986 y se ha ido extendiendo a partir de 1992 en Vietnam y Cambodia y a partir de 1995 en Costa Rica, donde existen actualmente unas 700 unidades en funcionamiento. Se reporta que en Colombia hay un número cercano a las 3.000 unidades en funcionamiento, en Vietnam existen actualmente alrededor de 5.000 unidades y en Cambodia 40.000 biodigestores de polietileno instalados (CIPAV, 2002). En el Ecuador no existen datos reportados sobre la utilización de esta tecnología.

El proceso de generación de energía eléctrica, a partir de biogás, consiste en que: el agua del lavado diario de los pisos e

\section{Tsafiquie}


instalaciones para el alojamiento y manejo de animales de granja es llevada por gravedad dentro del biodigestor. Allí se fermenta durante 20 a 50 días, hasta que la bolsa se infla continuamente, con el biogás producido por la fermentación de los excrementos disueltos en agua. Posteriormente este biogás se pasa por filtros con óxido de calcio disuelto en agua con limadura de hierro, donde se retiran el monóxido, el dióxido de carbono y el ácido sulfhídrico y se almacena el biogás purificado en otra bolsa plástica. De allí va a ser succionado por un compresor, que lo deposita y conserva a baja presión (entre 1 y 3 psi) en un tanque metálico, para luego utilizarlo para encender el motor, que mueve el generador de energía eléctrica.

\section{- Objetivos}

\section{- Objetivo General}

Generar gas metano a partir de un biodigestor mediante el aprovechamiento de los estiércoles generados por la ganadería

\section{- Objetivos Específicos}

- Aprovechar el estiércol generado de la actividad ganadera

- Evaluar los diferentes estiércoles en la generación de metano

- Evaluar la producción de energía alternativa del sistema

- Determinar la calidad del efluente para mitigar la contaminación

- Determinar los costos de producción de energía alternativa

\section{Materiales, Métodos y Procedimientos}

- Materiales por biodigestor

- Veinte y ocho metros de tubular en polietileno transparente calibre 8, de 5 metros de circunferencia.

- Un tubo de PVC de 6'

- Dos metros de manguera plástica transparente y flexible de $1 \frac{1}{4}$ pulgadas de diámetro.

- Un adaptador macho de PVC de 1'

- Un adaptador hembra de PVC de 1'

- Un T de PVC de 1' de diámetro.

- Dos codos de 90 grados de PVC de 1 pulgada de diámetro.

- Un tapón liso de PVC de 1 pulgada

- Cien cm de tubería gris de PVC de 1 pulgada de diámetro.

- Un frasco de pegante para PVC.

- Cincuenta $\mathrm{cm}$ de tubería metálica galvanizada de $1 / 2$ pulgada de diámetro.

- Dos arandelas en acrílico, madera, fibra de vidrio, aluminio o material sintético firme de $20 \mathrm{~cm}$. de diámetro con un agujero central de 1 pulgada.

- Un frasco plástico transparente, sin tapa, de 2 a 5 litros de capacidad.

- Dos empaques circulares de neumático usado de $25 \mathrm{~cm}$ de diámetro.

- Diez correas de neumático usado de $5 \mathrm{~cm}$ de ancho por 2 $\mathrm{m}$ de largo.

- Una alambrina o esponjilla metálica de lavar ollas.

\section{Procedimiento de instalación de los biodigestores}

1. Se excava la fosa en tierra de acuerdo a las necesidades del biodigestor considerando un ancho menor en la base y mayor en la parte superior 
Figura No 1.

Fosa de tierra para biodigestores

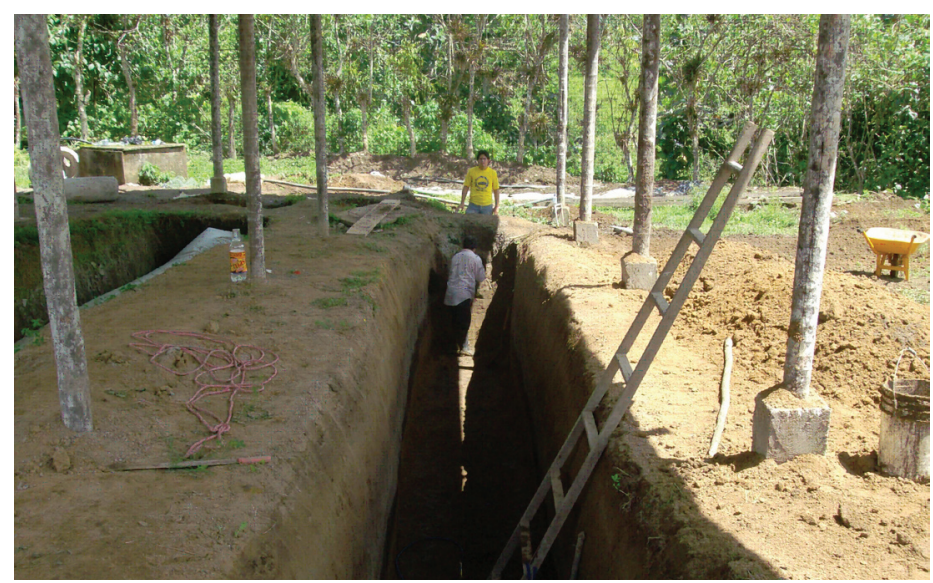

2. Se acondiciona la bolsa de polietileno, dejándola doble.

Figura No 2

Corte y extensión de la bolsa para luego introducir una dentro de la otra

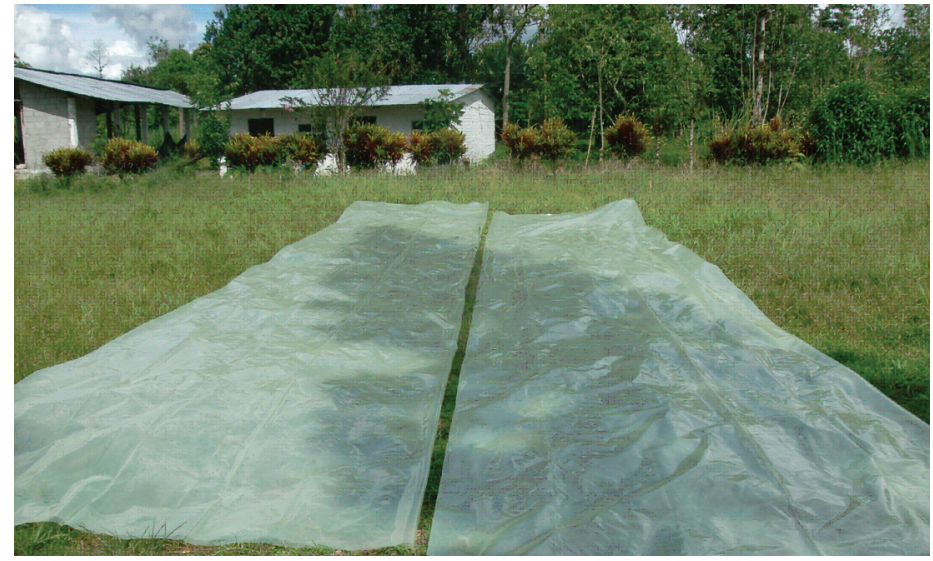

3. Se cortan los tubos de PVC de 6' y se procede el amarre con las correas de neumático
Figura No 3

Amarre de las correas para sujetar el plástico al tubo de PVC de 6'

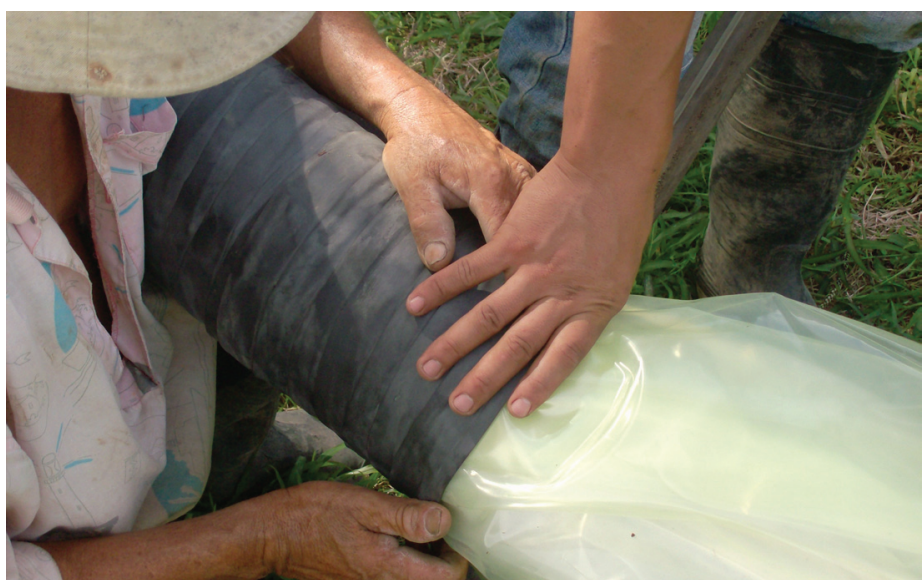

4. Se hace un orificio en la bolsa doble para colocar la válvula de salida para el gas.

5. Se arma y coloca la válvula de salida del biogás, ajustando los adaptadores macho y hembra, los dos empaques de neumático usado y las dos arandelas.

Figura. No 4

Válvula de salida instalada

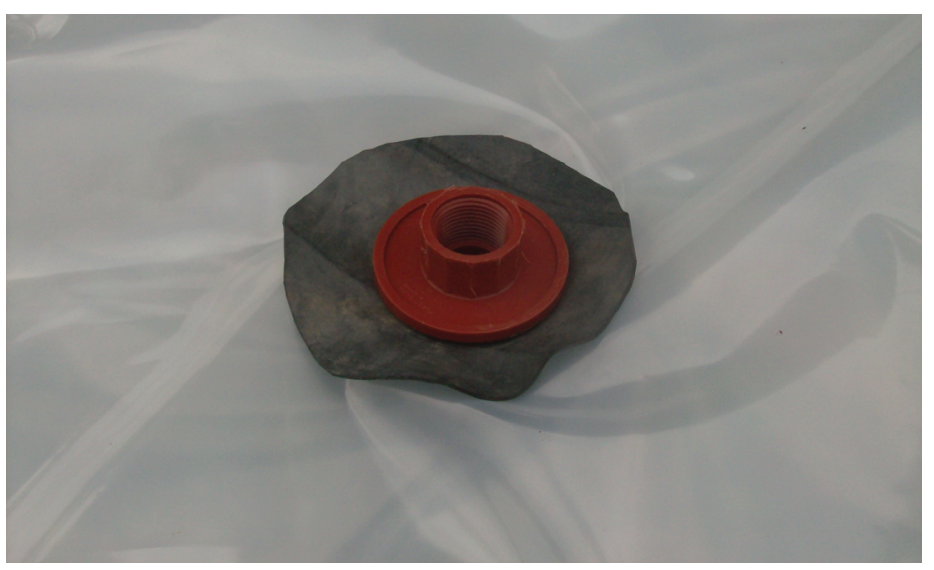

6. Se coloca la bolsa doble de polietileno dentro de la fosa. 
Figura No 5

Colocación de la bolsa dentro de la fosa

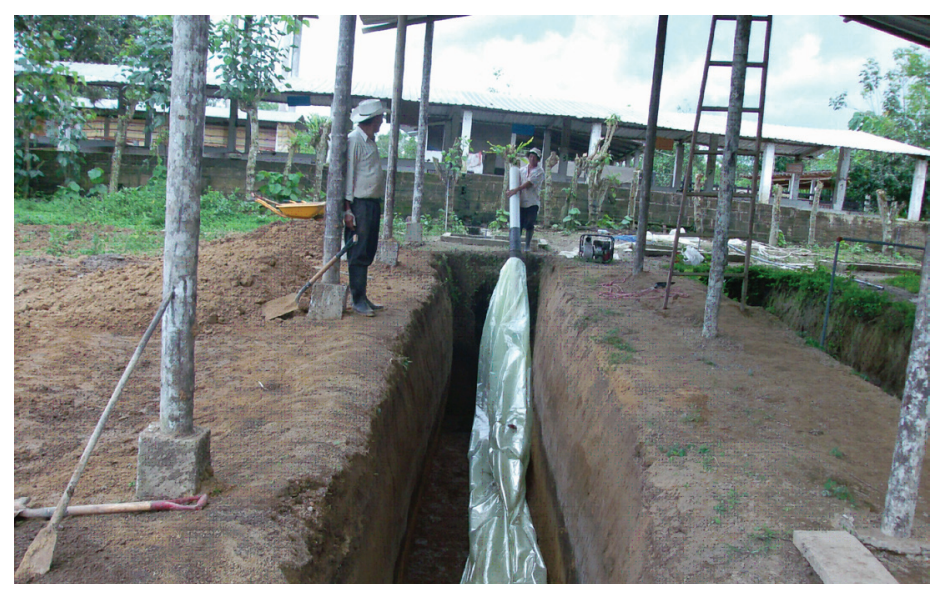

7. Ambos extremos de la bolsa se introducen en los tubos plásticos o alcantarillas y se amarran y sellan, utilizando para ello correas de neumático usado.

\section{Figura No 6}

\section{Sellado de la tubería de alcantarilla}

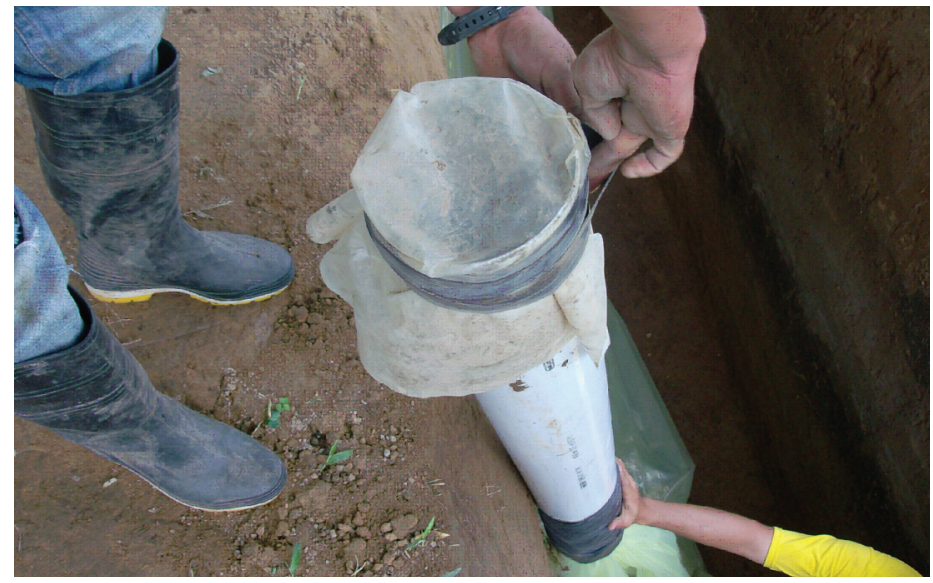

Figura No 7

Colocación de tubería en entrada y salida de entrada y salida

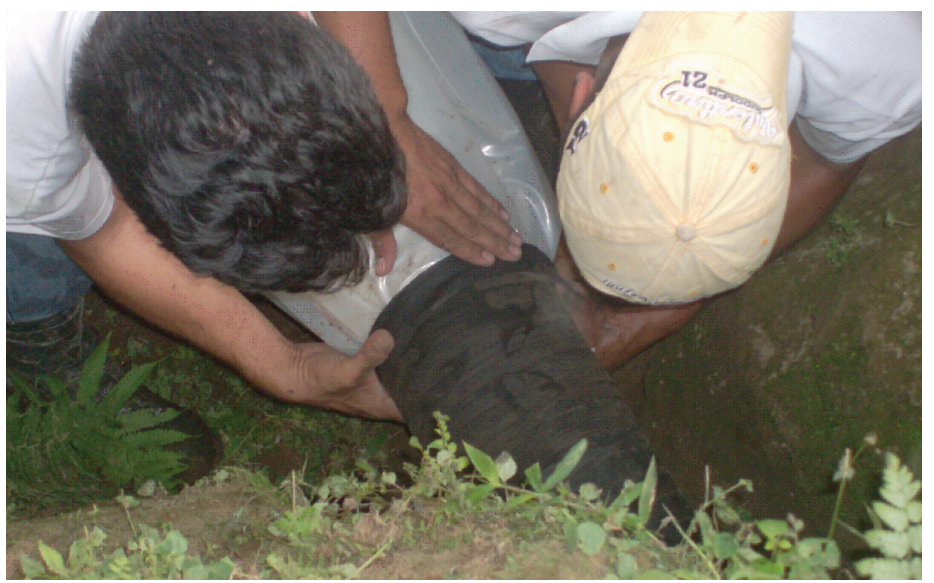

8. Se arma la válvula de seguridad, pegando niples, el codo y la T e introduciéndola dentro del frasco plástico de la válvula de seguridad.

Figura No 8

\section{Válvula de seguridad}

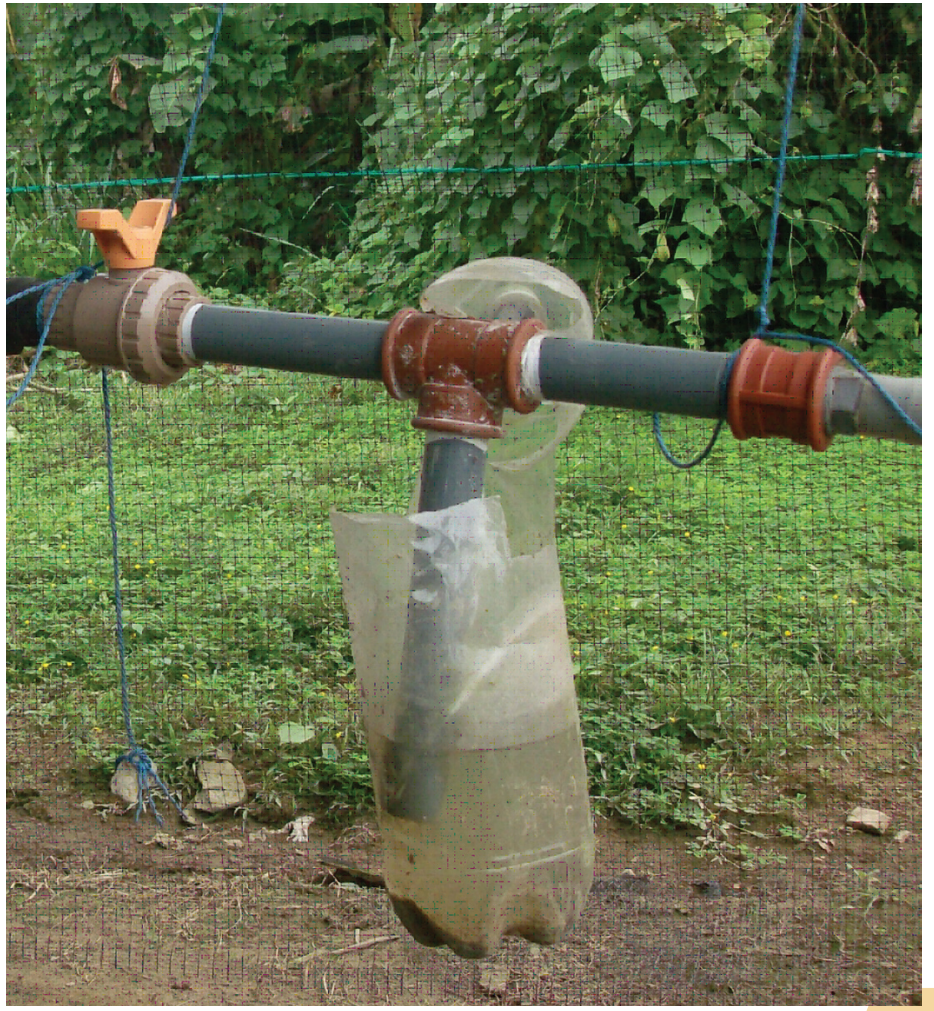


9.

Se inserta en ambos extremos la manguera plástica que une las válvulas de salida y de seguridad.

10. Se introduce una manguera de jardín usada, en el escape de un motor de combustible y su otro extremo se introduce dentro de la bolsa interna de polietileno.

Figura No 9

Manguera introducida el escape del carro

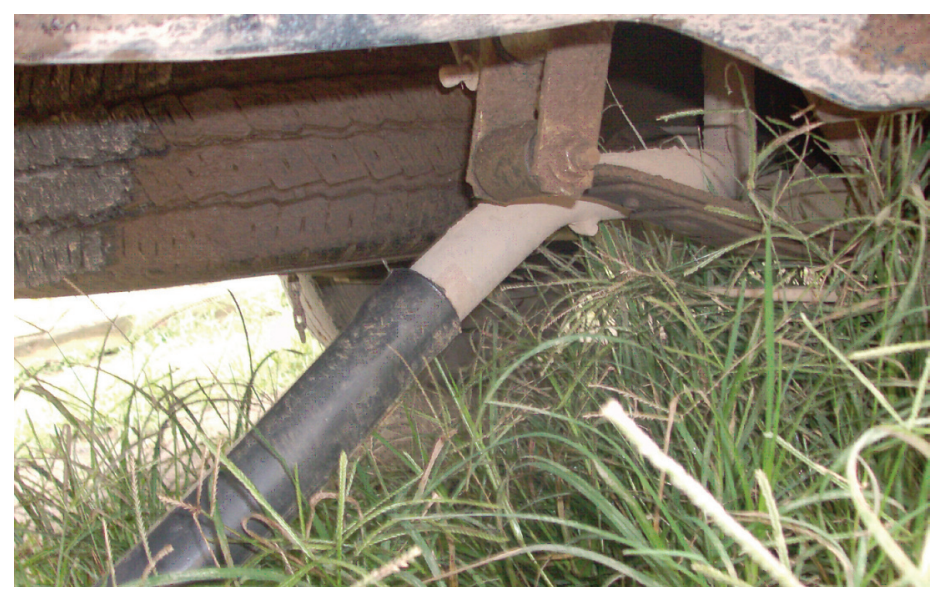

Figura No 10

El otro extremo en la alcantarilla y el biodigestor

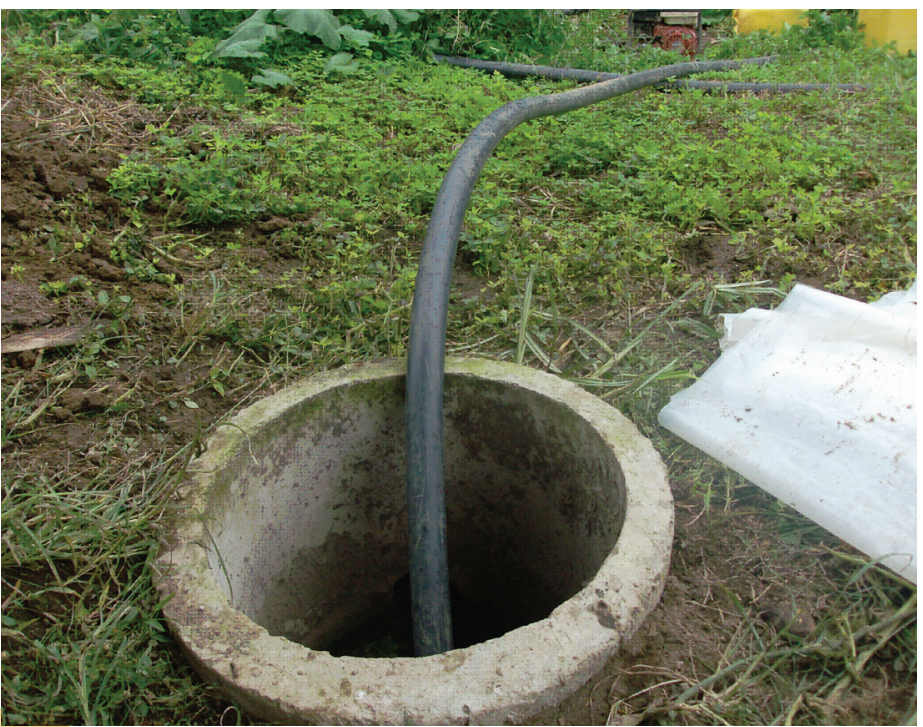

11. Se infla la bolsa con el humo de un motor para evitar las arrugas.

Figura No 11

\section{Proceso de inflado}

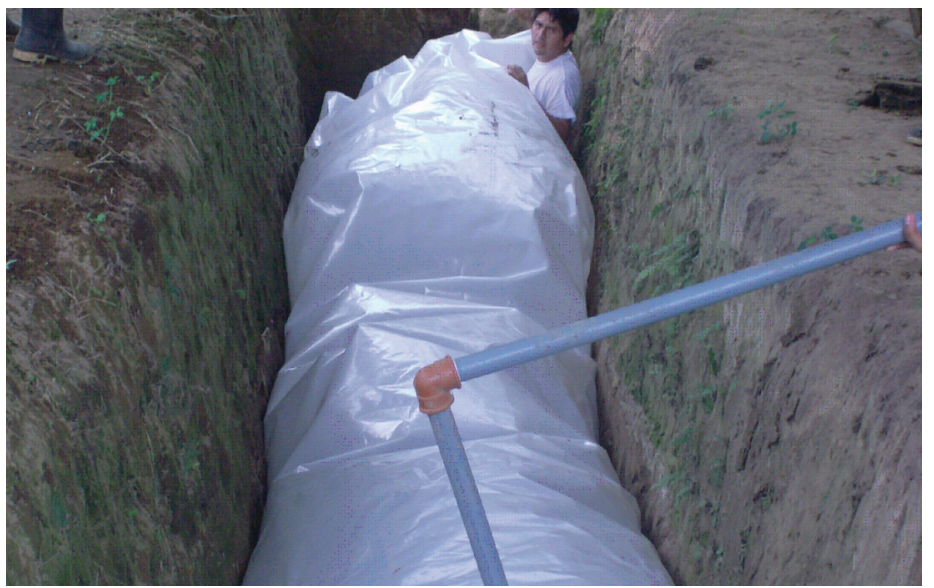

\section{Figura No 12}

\section{Biodigestor inflado}

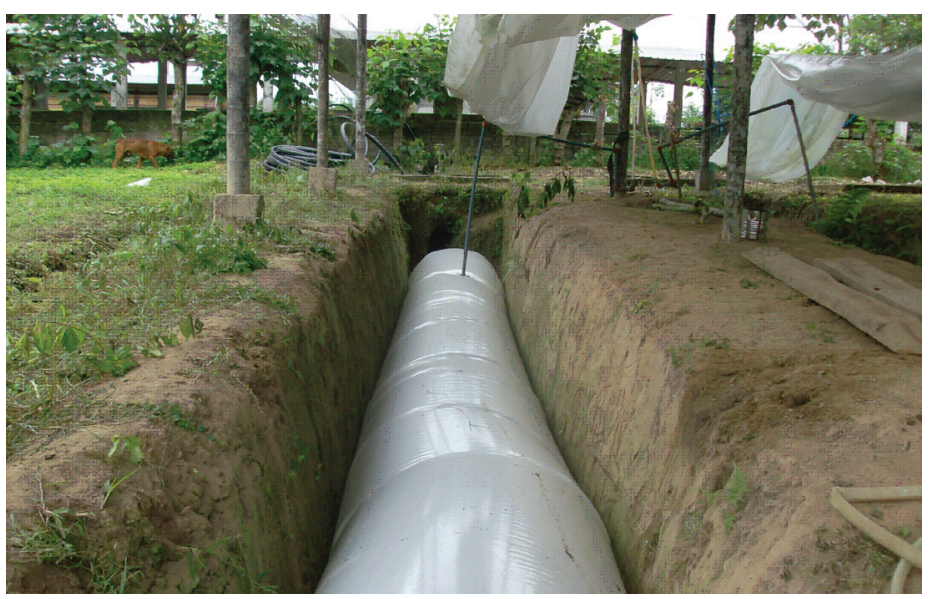

12. Se llena parcialmente la bolsa con agua y excretas para empezar el proceso. 
Figura No 13

Salida de agua

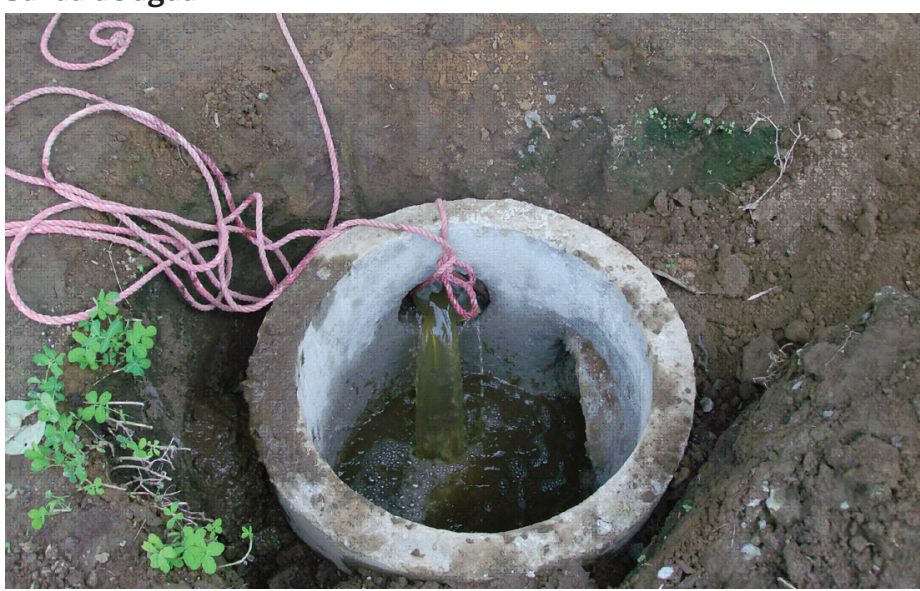

Figura No 14

\section{Salida de gas}

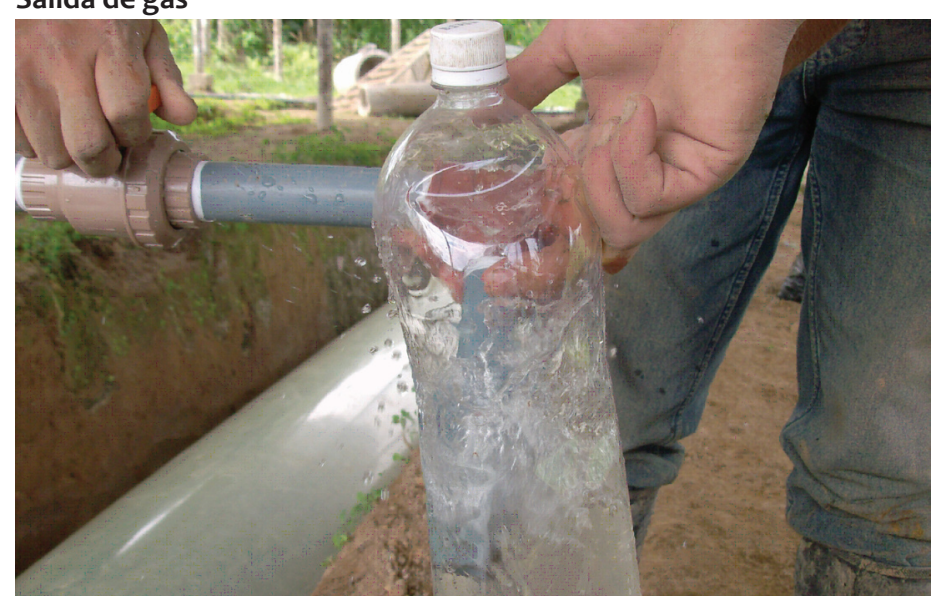

- Instalación de equipos para aprovechamiento de biogás

13. Instalación de reservorio de biogás
Figura No 15

\section{Bolsas de polietileno como reservorio y medición de biogás}

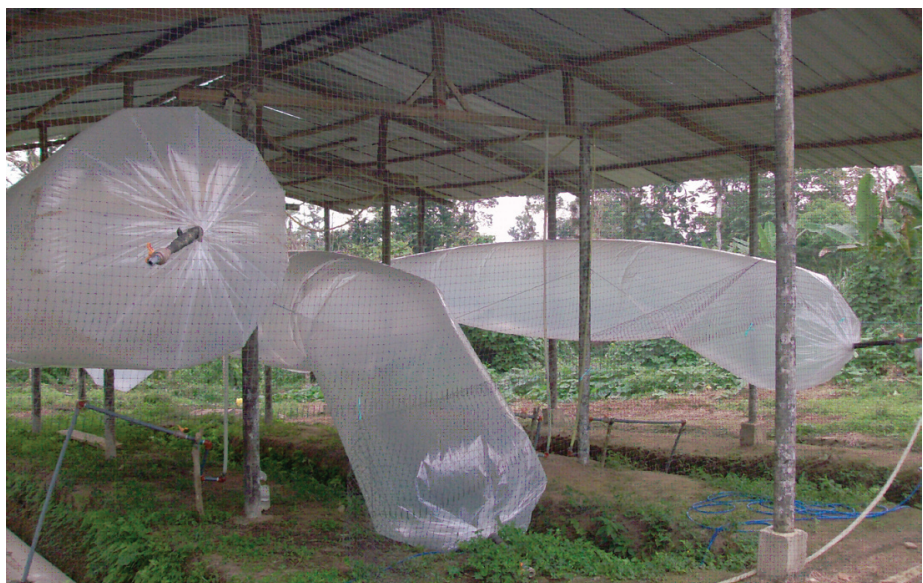

14. Distribución de biogás con mangueras de gas

Figura No 16

Salida de biogás con manguera

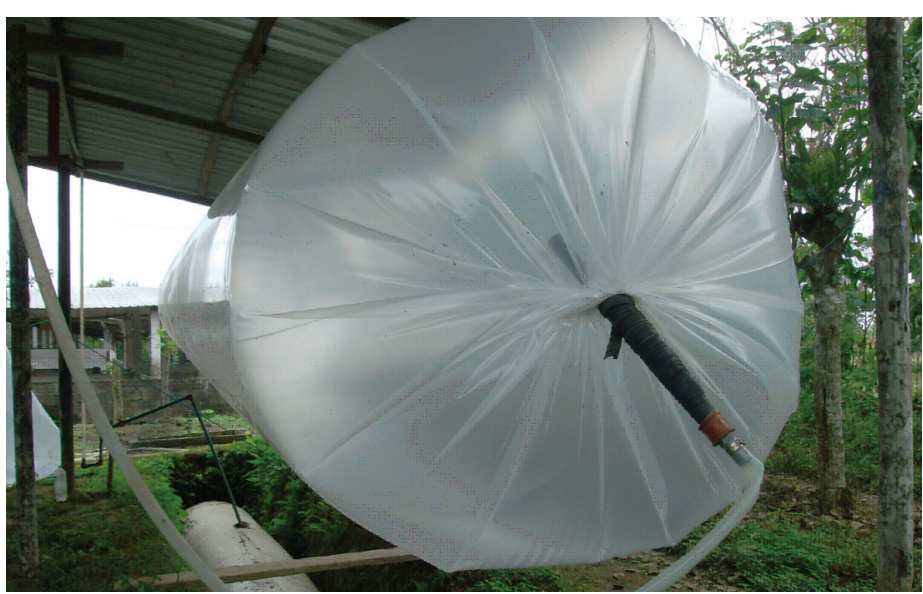

15. Recolección y compresión del gas por medio de un compresor 
Figura No 17

Compresor de 50 psi de presión y 0,5 hp de potencia

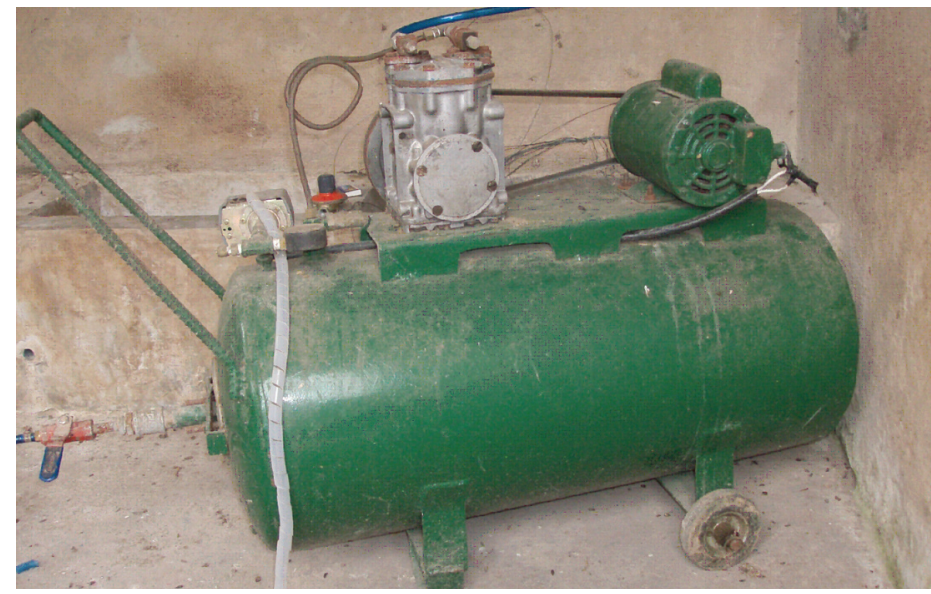

16. Instalación de hornilla industrial

Figura No 18

\section{Hornilla industrial}

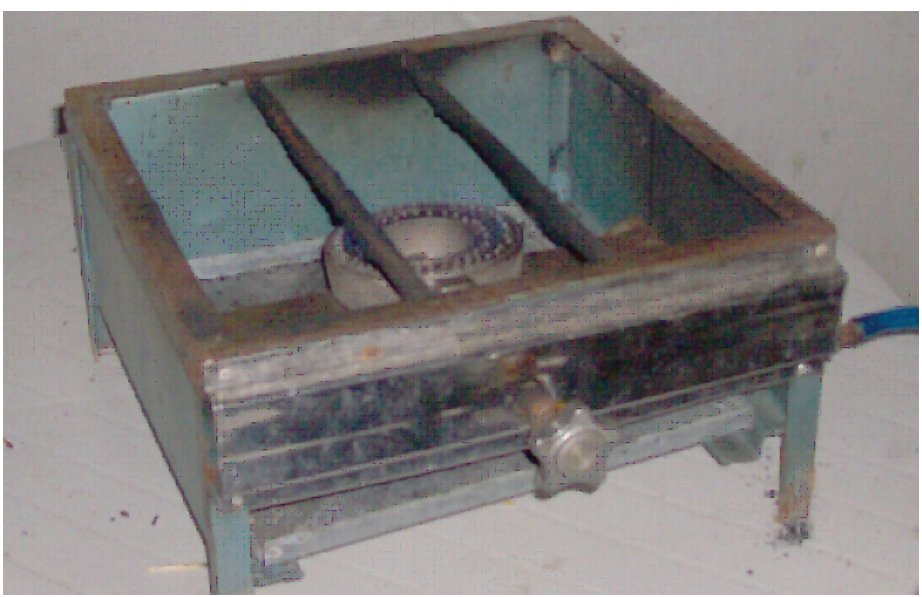

17. Conexión de generador de energía
Figura No 19

Generador de $5000 \mathrm{~W}$ a gas

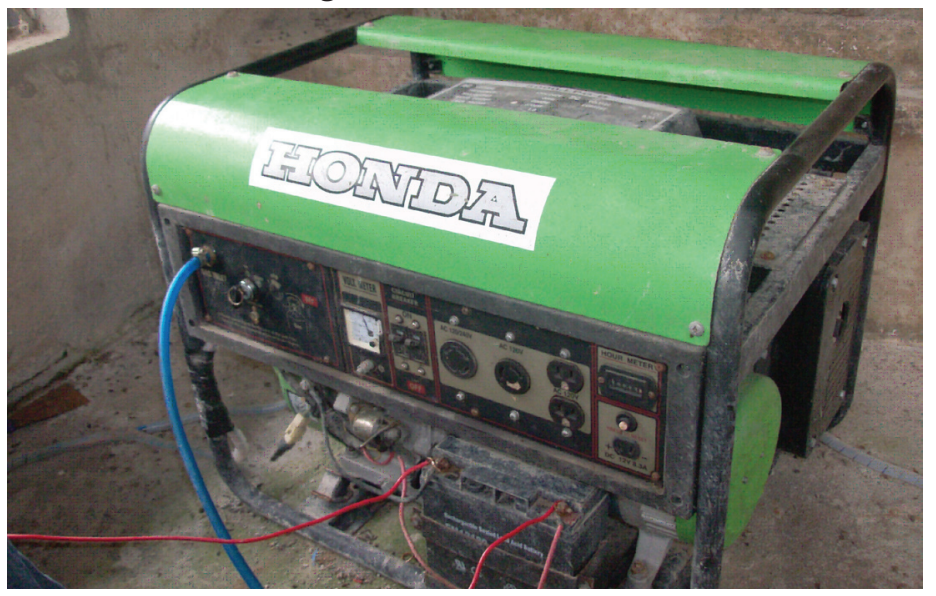

Figura No 20

Conexión gas, biogás con generador

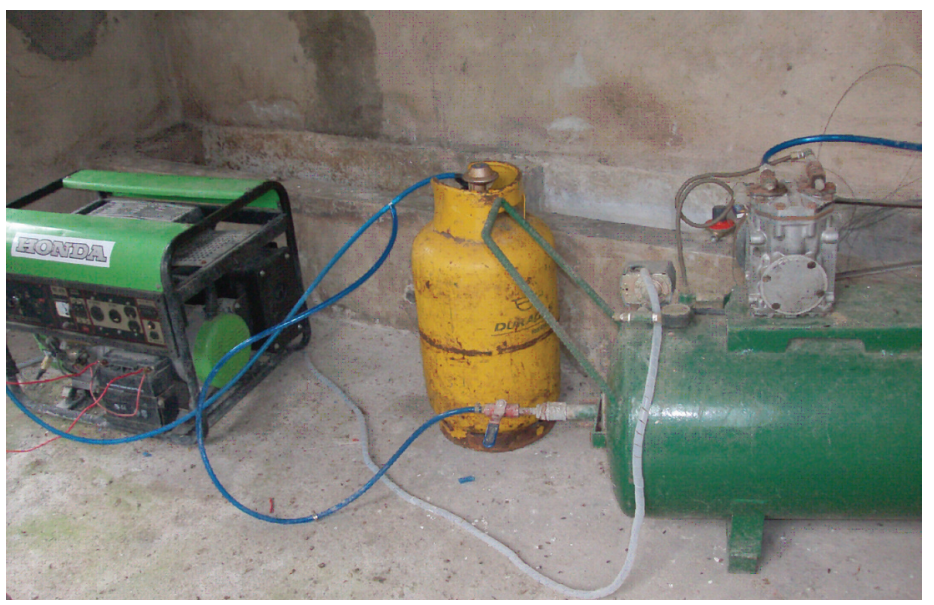

Figura No21

Traspaso de gas butano a metano (biogás)

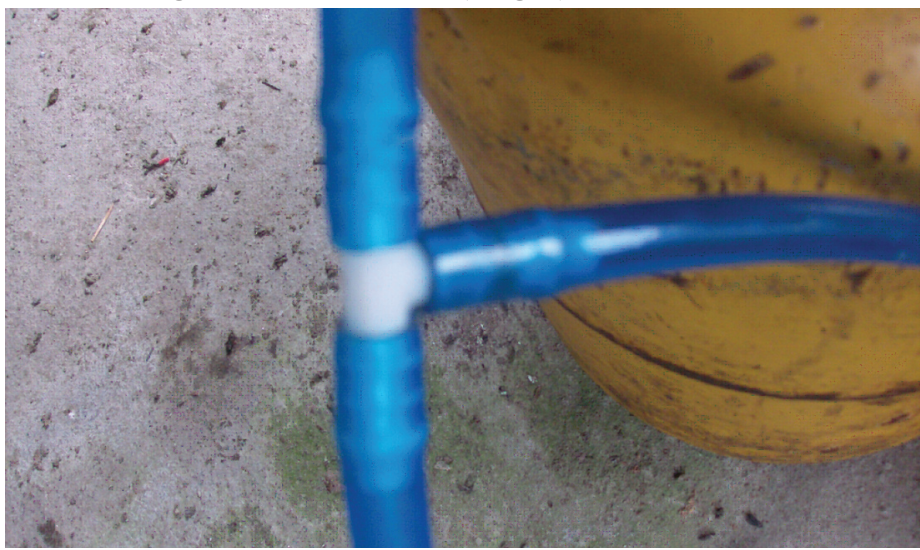




\section{Figura No22}

\section{Medición de amperaje generado}

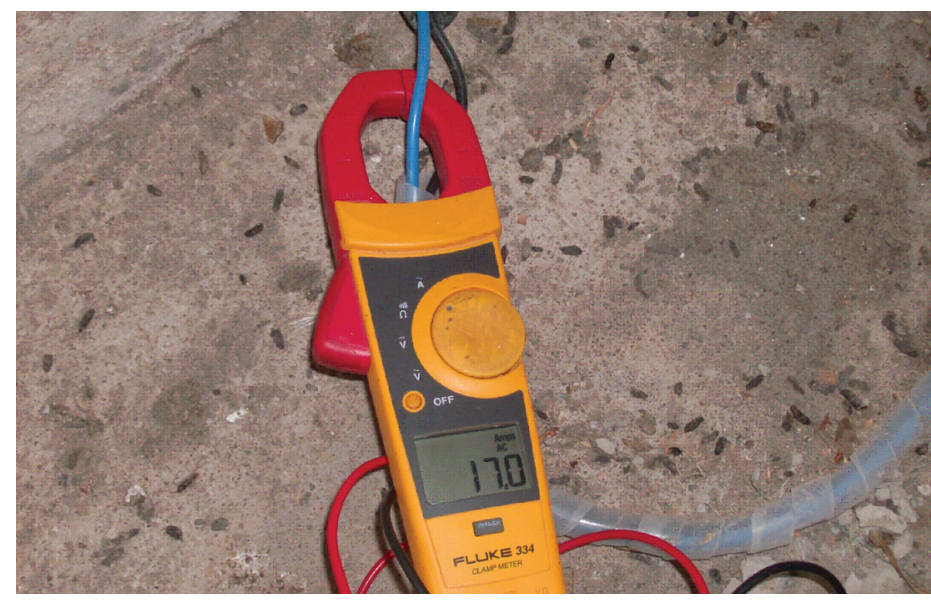

\section{- Ubicación}

Los biodigestores estarán ubicados lo más cerca posible de las porquerizas y el corral del ganado, aproximadamente a unos $20 \mathrm{~m}$. facilitando el acceso de los estiércoles.

\section{- Características del lote experimental}

Se tomó el estiércol del corral de bovinos, donde existe una población de 45 animales que pasan en el mismo por un periodo de 12 horas diarias, de la misma manera se procederá con el estiércol del corral de cerdos donde se encontraron 60 animales promedio en confinamiento.

\section{○ Número de biodigestores: 3 \\ ○ Largo del biodigestor: $12 \mathrm{~m}$ \\ ○ Diámetro del plástico: $2,5 \mathrm{~m}$}

o Profundidad del foso del biodigestor: $1,5 \mathrm{~m}$

o Separación entre biodigestores: 2 m

\section{- Factores en estudio}

- Cantidad de gas metano

- Calidad de gas, tiempo de llama y calor

- Cantidad de electricidad

o Calidad del efluente (DBO, DQO)

○ Análisis mineral del efluente

\section{- Tratamientos en estudio}

\section{Cuadro No 1}

Tratamientos en estudio

\begin{tabular}{|l|l|}
\hline Tratamientos & \\
\hline T1 & Biodigestor con estiércol bovino \\
\hline T2 & Biodigestor con estiércol porcino \\
\hline T3 & Biodigestor con los dos tipos de estiércoles (combinado) \\
\hline
\end{tabular}

- Análisis Estadístico

El análisis estadístico se determinará mediante las pruebas de Ji cuadrado y T de Student en un nivel de significación del 0,05.

\section{- Manejo del experimento}

Una vez iniciado el trabajo de investigación se realizó una adecuación a los corrales de los cerdos y bovinos identificando el lugar por donde se va llevó los desechos que fueron utilizados en el biodigestor por medio de canales de cemento con un 10\% de pendientes separados según su procedencia.

Los estiércoles fueron separados en sólidos y líquidos para luego los líquidos utilizarlos en el biodigestor y el sólido en la elaboración de diferentes tipos de abonos orgánicos. 
Se construyeron 3 biodigestores mediante el método de flujo continuo (bolsas de plástico) de $12 \mathrm{~m}$. de largo x 2,5 de diámetro en una misma estructura techada que corresponderán a tres tratamientos (T1 Bovinos, T2 Porcinos y T3 Combinado).

Para la evaluación se midió a la salida de los biodigestores la calidad y cantidad del gas metano producido por un periodo de tres meses, además de la calidad de agua al momento de entrada y salida por medio de las pruebas químicas de DBO y DQO.

En la segunda fase se adecuó un generador eléctrico donde se midió la cantidad y calidad de energía eléctrica producida. Se calculó la capacidad del generador tomando en cuenta los datos obtenidos en la evaluación del biodigestor, la disponibilidad del generador y los recursos económicos del proyecto.

El gas producido se lo almacenó en una bolsa de polietileno del mismo tamaño que el biodigestor en la parte superior del mismo, de donde se pasó por un filtro para ser llevado a un tanque de presión con la ayuda de un compresor que estuvo conectado al motor de generación donde fue medida la cantidad y calidad de la energía.

Se determinó los costos de producción del sistema de generación de gas y electricidad.

\section{Resultados y Discusión}

\section{- Aprovechamiento del estiércol}

Para el aprovechamiento del estiércol de la finca OASIS al inicio del proyecto se realizó una evaluación de la cantidad de estiércol producido diariamente tanto de bovinos como de porcinos para poder dimensionar a los biodigestores. En el caso de los bovinos se utilizó como referencia el número de animales promedio que pasan en el corral por un periodo de 12 horas. En el caso de los porcinos se realizó una estimación de animales promedios en la porqueriza tomando en consideración principalmente el número de madres y reproductores con que se contaba en ese momento.

Otro parámetro que se consideró fue la cantidad de agua utilizada para el lavado de los corrales y la frecuencia de este. La frecuencia fue diaria por lo que se consideró realizar canales directos desde el corral de cerdos y bovinos a los biodigestores para el tratamiento 1 y 2 mientras que el tratamiento 3 se utilizó una canaleta directa desde el corral de bovinos por poseer la mayor cantidad de estiércol y hacer la aplicación de estiércol porcino manualmente.

Como se puede observar en el Cuadro No 2, la cantidad de estiércol bovino superaba a la de porcino e inicialmente se planificó la consecución de estiércol porcino de una porqueriza cercana para suplir la cantidad faltante del mismo para los diferentes tratamientos. Esto no se realizó ya que en el transcurso del proyecto la explotación de porcinos aumento en un $100 \%$ aproximadamente no teniendo necesidad de realizar una incorporación de estiércol de otro sitio.

\section{Cuadro No 2}

Cantidad de animales en la finca EL OASIS y estiércol aprovechable al inicio del proyecto

\begin{tabular}{|l|r|r|r|r|}
\hline \multicolumn{1}{|c|}{ Categoría } & Animales & $\begin{array}{c}\text { Cantidad } \\
\text { Estiércol por } \\
\text { animal (kg/día) }\end{array}$ & Tiempo (día) & $\begin{array}{c}\text { Total Estiércol } \\
\text { (kg/día) }\end{array}$ \\
\hline Bovinos & 20 & 24 & 0,5 & 240 \\
\hline Porcinos & 25 & 4 & 1 & 100 \\
\hline
\end{tabular}

Tomando en consideración la cantidad de estiércol producido en la finca se realizó el cálculo del tamaño de biodigestores.

\section{- Cálculo de tamaño de los biodigestores}

Para el cálculo del tamaño de los biodigestores se tomó en cuenta la cantidad de estiércol producido en la finca OASIS, tamaño de las fundas en el mercado nacional, espacio de terreno con que se contaba y capacidad de compra del proyecto. En lo que respecta al plástico este tiene que ser enviado a construir con las dimensiones 
que se requieran ya que en el país no existe ninguna empresa que lo realice de forma consecutiva, lo que dificulta y demora la construcción de biodigestores de flujo continuo. El tamaño que se ofreció de parte de la casa comercial estaba entre 4 a $8 \mathrm{~m}$ de circunferencia por el largo que se pidiera y el tiempo que se demora la empresa en su construcción es de dos a tres semanas.

Para este cálculo se utilizó una medida de plástico de cinco metros de circunferencia lo que nos dió un diámetro de 1,59 m. cercano a lo que enuncia la literatura de 1,5 m., el largo de $12 \mathrm{~m}$. utilizables, el volumen del biodigestor estaría considerado en un $75 \%$ de líquido (mezcla estiércol-agua) y un $25 \%$ de biogás, una permanencia del liquido en el interior del biodigestor de 30 días y una relación de estiércol agua de $1 \mathrm{~kg}$ de estiércol por $4 \mathrm{~kg}$ de agua.

En los cálculos realizados en el Cuadro No 3, se pudo observar que la cantidad de estiércol necesario para alimentar el biodigestor de $5 \mathrm{~m}$ de circunferencia por $12 \mathrm{~m}$ de largo fue suficiente inicialmente en el caso de los bovinos no así en el caso de los porcinos donde existió la necesidad de suplir el faltante de otro sitio o de aumentar el número de animales en confinamiento para esta finalidad como lo sucedido en esta investigación.

\section{Cuadro No 3}

Cálculos de recambio de líquido en el biodigestor diariamente de acuerdo a la circunferencia del plástico utilizado en 12 metros de largo útiles

\begin{tabular}{|c|r|r|r|r|r|r|r|}
\hline $\begin{array}{c}\text { Circunferencia } \\
(\mathbf{m})\end{array}$ & $\begin{array}{c}\text { Diámetro } \\
(\mathbf{m})\end{array}$ & $\begin{array}{c}\text { Radio } \\
(\mathbf{m})\end{array}$ & $\begin{array}{c}\text { Volumen } \\
\left(\mathbf{m}^{\mathbf{3}}\right)\end{array}$ & $\begin{array}{c}\text { Liquido } \\
\mathbf{7 5 \%} \\
(\mathbf{m} 3)\end{array}$ & $\begin{array}{c}\text { Gas } \\
\mathbf{2 5 \%} \\
(\mathbf{m} 3)\end{array}$ & $\begin{array}{c}\text { Volumen } \\
\text { diario } \\
(\mathbf{m} 3)\end{array}$ & $\begin{array}{c}\text { Estiércol } \\
\text { día (1-4) } \\
(\mathbf{k g})\end{array}$ \\
\hline 4 & 1,27 & 0,64 & 15,28 & 11,46 & 3,82 & 0,382 & 76,39 \\
\hline 4,7 & 1,50 & 0,75 & 21,21 & 15,90 & 5,30 & 0,530 & 106,03 \\
\hline 5 & 1,59 & 0,80 & 23,87 & 17,90 & 5,97 & 0,597 & 119,37 \\
\hline 6 & 1,91 & 0,95 & 34,38 & 25,78 & 8,59 & 0,859 & 171,89 \\
\hline 7 & 2,23 & 1,11 & 46,79 & 35,09 & 11,70 & 1,170 & 233,96 \\
\hline 8 & 2,55 & 1,27 & 61,12 & 45,84 & 15,28 & 1,528 & 305,58 \\
\hline
\end{tabular}

Los datos del cuadro No 3 sirven para poder calcular el tamaño exacto de los biodigestores de flujo continuo dependiendo de la cantidad de estiércol promedio producida en la propiedad y la cantidad de agua que se necesita para su buen y normal funcionamiento. El productor deberá tomar en cuenta la cantidad promedio de animales con que cuenta su propiedad y su proyección en el tiempo si lo que quiere es crecer.

\section{- Valores de pH}

El pH óptimo para lograr mayor eficiencia en la producción de biogás es de 6,7 a 7,5 (Griffis et al 1980 citado por CIPAV 1995). El pH se mantiene en ese rango sólo si el biodigestor opera correctamente. Si se torna muy ácido, la acción de las bacterias metano génicas inhibe y aumenta la producción de gas carbónico en el biogás (Taiganides et al 1963 citado por CIPAV 1995).

Las causas por las que se puede acidificar la fase líquida contenida dentro del biodigestor son el cambio excesivo de la carga, permanencia por largo tiempo sin recibir carga, presencia de productos tóxicos en la carga y cambio amplio y repentino de la temperatura interna. La alta acidez se puede corregir al adicionar agua con cal a la fase líquida.

Los valores correspondientes a pH demuestran un buen proceso de descomposición y producción de metano en todos los tratamientos evaluados. Los pH iníciales de todos los tratamientos son alcalinos debido a la alimentación que tienen los animales en la propiedad.

\section{Tsafiqu}




\section{Cuadro No 4}

Valores de análisis básico de calidad de aguas y las normativas nacional e internacional

\begin{tabular}{|c|c|c|c|c|c|c|c|}
\hline Sitio de Muestreo & $\begin{array}{c}\text { DQO } \\
m g / l t\end{array}$ & $D^{\prime} O_{5}$ & S.S.T & $\begin{array}{c}\text { Grasas } \\
y \\
\text { aceites } \\
m g / l\end{array}$ & $p H$ & Temperatura & $\begin{array}{c}\text { Sólidos } \\
\text { Sedimentables } \\
m I / I\end{array}$ \\
\hline $\begin{array}{c}\text { Entrada } \\
\text { biodigestor bovino }\end{array}$ & 3190 & 1400 & 382 & 221 & 8,5 & 24 & 120 \\
\hline $\begin{array}{c}\text { Salida biodigestor } \\
\text { bovino }\end{array}$ & 165 & 9,2 & 125 & $<8$ & 6,75 & 25 & 2 \\
\hline $\begin{array}{c}\text { Entrada } \\
\text { biodigestor } \\
\text { porcino }\end{array}$ & 3300 & 1700 & 289 & 265 & 8,48 & 23 & 100 \\
\hline $\begin{array}{c}\text { Salida biodigestor } \\
\text { porcino }\end{array}$ & 180 & 45 & 101 & $<8$ & 6,49 & 23 & 0,9 \\
\hline $\begin{array}{c}\text { Entrada } \\
\text { biodigestor mixto }\end{array}$ & 3252 & 1583 & 255 & 333 & 8,3 & 24 & 130 \\
\hline $\begin{array}{c}\text { Salida biodigestor } \\
\text { mixto }\end{array}$ & 162 & 10,8 & 124 & $<8$ & 6,6 & 24 & 1,3 \\
\hline NORMAS CIIU* & 800 & 500 & 200 & 30 & $5 a 9$ & $15 a 40$ & 1 \\
\hline $\begin{array}{c}\text { Limites descarga } \\
\text { alcantarillado }\end{array}$ & 500 & 250 & 220 & 100 & 6 a 9 & $<40$ & 20 \\
\hline $\begin{array}{c}\text { Limites descarga } \\
\text { cuerpo agua dulce }\end{array}$ & 250 & 100 & - & 0,3 & & $<35$ & - \\
\hline
\end{tabular}

*Código Internacional Industrial Unificado, Límites descarga alcantari-

llado y cuerpo de agua dulce fuente: Norma de calidad ambiental y de descarga de efluentes: recurso agua.

\section{- Influencia de la temperatura}

La tasa de fermentación anaeróbica de los sólidos orgánicos y su conversión parcial en biogás están directamente relacionadas con la temperatura interna de operación y por ende de la temperatura ambiental del sitio donde se realice el biodigestor. El proceso se lleva a cabo en un amplio rango de temperatura que va desde 15 a 60 grados centígrados, la mayor eficiencia de conversión se obtiene en los rangos de temperatura mesolíticos $\left(30 \mathrm{a} 40^{\circ} \mathrm{C}\right)$ y termofílicos $\left(55 \mathrm{a} 60^{\circ} \mathrm{C}\right)$. La mayoría de bacterias metano génicas digieren la materia orgánica más eficientemente en el rango mesolítico que puede ser alcanzado por la fase líquida, no solamente por efecto de la temperatura ambiental sino también por la temperatura interna.

Esta se incrementa debido a la generación de calor ocurrida durante la fermentación de la materia orgánica (proceso exotérmico); por esta razón, a medida que disminuye la temperatura ambiental por efecto de la altura sobre el nivel del mar, es conveniente recolectar el agua de lavado de las instalaciones pecuarias para la alimentación del biodigestor, bien durante las horas más cálidas del día o utilizando calentadores solares para ello. (Botero, 1999)

De los datos del cuadro No 4 se puede observar que la temperatura inicial como final es menor a lo requerido para una mejor eficiencia de conversión lo que nos indica que se podría calcular la capacidad del biodigestor con un mayor número de días de permanencia no como lo que se calculó a 30 días. Según el CIPAV el tiempo de retención para la digestión anaeróbica de la materia orgánica diluida es de 50 días; en clima caliente $\left(>30^{\circ} \mathrm{C}\right)$ se baja a 40 ó 30 días. La cantidad diaria de excretas para alimentar el biodigestor se calcula dividiendo el volumen de su fase líquida entre 50 días de retención.

\section{Cuadro No 5}

Relación entre temperatura, tiempo de retención y eficiencia de producción de Biogas

\begin{tabular}{|c|c|c|c|}
\hline Temperatura(으) & $\begin{array}{c}\text { Tiempo de } \\
\text { Retención (días) }\end{array}$ & $\begin{array}{c}\text { Eficiencia }(\mathrm{m} 3 \\
\text { biogás } / \mathrm{m} 3 \\
\text { biodigestor) }\end{array}$ & Calefacción \\
\hline 10 a 25 & 50 a 70 & 0,01 a 0,3 & No \\
\hline 30 a 40 & 20 a 30 & 0,7 a 1,0 & $\mathrm{Si}$ \\
\hline 40 a 55 & 10 a 20 & 1,0 a 2,0 & $\mathrm{Si}$ \\
\hline
\end{tabular}

Fuente:

INTA,2005

Según INTA (2005), Cuadro No 5 la temperatura está relacionada inversamente proporcional es decir mientras mayor sea la temperatura menor será el tiempo de retención necesario para la producción de biogás y viceversa mientras menor sea la temperatura mayor será el tiempo de retención o permanencia. Adicional a esto la eficiencia de producción ( $\mathrm{m} 3$ biogás / m3 biodigestor) será mucho mejor a mayor temperatura, pero para esto será necesario la utilización de calefacción. En Santo Domingo lugar de la investigación la temperatura promedio es de $23^{\circ} \mathrm{C}$ lo que según CIPAV e INTA tendría que tener una permanencia de mínima de 50 días. 


\section{- Proporción de excretas y Agua}

Las excretas sólidas (estiércol) contienen en promedio $20 \%$ de materia seca. Deben ingresar al biodigestor como una suspensión en agua del 4 al 5\% de materia seca; esto significa en términos prácticos una mezcla de cuatro partes de agua por una parte de estiércol fresco. Se pueden utilizar hasta diez partes de agua por una de estiércol, según el número y especie de animales; por ejemplo, el estiércol de cerdo es más metano génico que el de otras especies animales.

Al tomar la decisión de realizar canaletas directas desde los corrales hasta los biodigestores se evitó la medición de este parámetro y mano de obra a utilizarse en la mezcla del agua con el estiércol. A pesar de esto en la época de invierno existió la necesidad de realizar una desviación del agua lluvia para evitar la dilución de la mezcla. Otro de los factores encontrados durante la investigación fue que en ciertas épocas del año el personal por evitar pérdidas de agua en época de escases, o exceso de número de animales en el corral, se utilizó una dilución escasa lo que ocasionó problemas de sedimentación y baja producción de gas, que se pudieron arreglar con la entrada de agua pura en gran cantidad.

Otra de las formas de dar solución a esto es la construcción de un sedimentado donde los sólidos queden atrapados en este y puedan ser utilizados en producción de abonos orgánicos. Es de suma importancia medir la cantidad de estiércol y agua constantemente para verificar su proporción.

\section{- Descontaminación de Aguas}

Es importante que los biodigestores sirvan como procedimiento para cumplir con la normativa nacional e internacional de descarga de efluentes a vertientes de agua. En el Cuadro No 4 se puede observar que tanto la normativa nacional de Limites de descarga al sistema de alcantarillado público como la de límites de descarga a un cuerpo de agua dulce y al Código Internacional Industrial Unificado se cumplen en los parámetros enunciados de demanda química de oxígeno
(DQO), Demanda bioquímica de oxigeno 5 días (DQO 5), Sólidos suspendidos totales (S.S.T.), grasas y aceites, Sólidos Sedimentables, pH y temperatura ya que todos los parámetros solicitados se cumplen a cabalidad luego del proceso del biodigestor.

Cabe destacar que esta agua no puede ser utilizada ni para alimentación animal ni mucho menos para usos humanos para poder realizar esto se tiene que seguir con un proceso de filtración en lagunas de oxidación y sedimentación. Si podría ser utilizada en procesos de riego en cultivos que no sean de consumo fresco ya que por la cantidad de bacterias podrían causar efectos negativos de contaminación.

\section{- Composición y características del Biogás}

Se llama biogás a la mezcla constituida por metano $\mathrm{CH}_{4}$ en una proporción que oscila entre un 50\% a un 70\% y dióxido de carbono conteniendo pequeñas proporciones de otros gases como hidrógeno, nitrógeno y sulfuro de hidrógeno. Es importante conocer esta composición para entender con el tipo de gas que se está manipulando y conocer su peligrosidad en la producción ganadera. A pesar que en la investigación no se realizó ningún análisis de este biogás se consideró importante revisar en la literatura su composición como lo enuncia el Cuadro No 6.

Como se observa en el Cuadro No 6, existe la presencia de sulfuro de hidrógeno lo que en combinación con agua puede convertirse en ácido sulfúrico esto puede ocasionar daño corrosivo a los metales. Es por esta razón que se utiliza alambrina o también llamado lustre en el filtro para evitar esta formación de ácido. 


\section{Cuadro No 6}

\section{Composición y características del biogás}

\begin{tabular}{|c|c|c|c|c|c|}
\hline Características & $\mathrm{CH} 4$ & $\mathrm{CO} 2$ & $\mathrm{H} 2-\mathrm{H} 2 \mathrm{~S}$ & Otros & Biogás 60/40 \\
\hline Proporciones \% volumen & $55-70$ & $27-44$ & 1 & 3 & 100 \\
\hline Valor Calórico & \multirow[b]{2}{*}{35,8} & \multirow[b]{2}{*}{ - } & \multirow[b]{2}{*}{10,8} & \multirow[b]{2}{*}{22} & \multirow[b]{2}{*}{21,5} \\
\hline $\mathrm{MJ} / \mathrm{m} 3$ & & & & & \\
\hline $\mathrm{Kcal} / \mathrm{m} 3$ & 8600 & - & 2581 & 5258 & 5140 \\
\hline Ignición \% en aire & 5 a 15 & - & - & - & 6 a 12 \\
\hline Tempe. Ignición en 으 & 650 a 750 & - & - & - & 650 a 750 \\
\hline Presión crítica en Mapa & 4,7 & 7,5 & 1,2 & 8,9 & 7,5 a 8,9 \\
\hline Densidad nominal en $\mathrm{g} / \mathrm{l}$ & 0,7 & 1,9 & 0,08 & - & 1,2 \\
\hline Densidad relativa & 0,55 & 2,5 & 0,07 & 1,2 & 0,83 \\
\hline $\begin{array}{l}\text { Inflamabilidad Vol. en \% } \\
\text { aire }\end{array}$ & 5 a 15 & - & - & - & 6 a 12 \\
\hline
\end{tabular}

Fuente: INTA, CIPAV, EARTH, entre otros

Es importante observar el Cuadro No 6. que la temperatura de ignición es de $650^{\circ} \mathrm{C}$ lo que hace que en temperatura ambiente no exista problema alguno de almacenarlo sin riesgo, a pesar de esto se tiene que considerar medidas de precaución ya que es un gas inflamable pero necesita de aire (oxígeno) para esto por lo cual puede ser manejado fácilmente.

\section{- Producción de biogás}

Luego de realizada la prueba de T Student no existen diferencia significativas entre los tratamientos T1 y T2; T1 y T3; T2 y T3 a pesar que se puede observar en el Cuadro No 7 que si existen diferencias numéricas entre los tratamientos siendo el de mayor producción de biogás el tratamiento con estiércol porcino seguido del estiércol combinado y al final el estiércol bovino. Lo que concuerda con lo enunciado por Botero y otros autores donde se enuncia que el estiércol porcino por su composición es más metano génico es decir produce mayor cantidad de biogás. Es por esto que tanto el tratamiento con 100\% de estiércol porcino como el de 50\% de porcino con bovino tienen mayor producción de gas.

\section{Cuadro No 7}

Producción de biogás y eficiencia de los diferentes tratamientos

\begin{tabular}{|r|r|r|r|r|}
\hline Tratamiento & \multicolumn{1}{|c|}{ Nombre } & $\begin{array}{c}\text { Producción } \\
\text { diaria (m3) }\end{array}$ & $\begin{array}{c}\text { Producción } \\
\text { anual estimada } \\
\text { (m3) }\end{array}$ & $\begin{array}{c}\text { Eficiencia (m3 } \\
\text { biogás } / \mathbf{m 3} \\
\text { digestor) }\end{array}$ \\
\hline 1 & Estiércol bovino & 2,7 & 985,5 & 0,15 \\
\hline 2 & Estiércol porcino & 3,0 & 1095,0 & 0,17 \\
\hline 3 & Estiércol mixto & 2,8 & 1022,0 & 0,16 \\
\hline & TOTAL & 8,5 & 3102,5 & \\
\hline
\end{tabular}

En el Cuadro No 7 se observa que la eficiencia de producción de biogás en metros cúbicos por metros cúbicos del biodigestor es normal en las condiciones de temperatura presentadas pudiendo ser posiblemente mejores si se utiliza mayor cantidad de días de retención. A pesar de esto la cantidad de biogás producida diariamente y anualmente en la finca EL OASIS es significativa para los usos que se pueden dar, adicional a esto se puede aumentar su producción siendo más eficiente en los días de retención y en incrementar mayor número de biodigestores ya que el sistema en la actualidad lo puede sustentar por el aumento de animales y de días de retención.

\section{- Usos y su evaluación}

En principio el biogás puede ser utilizado en cualquier tipo de equipo comercial para uso de gas natural como se observa en el Gráfico No 12 especialmente como gas para la cocción de alimentos y en motores para producción de energía eléctrica.

\section{Grafico No 23}

\section{Usos del Biogás}

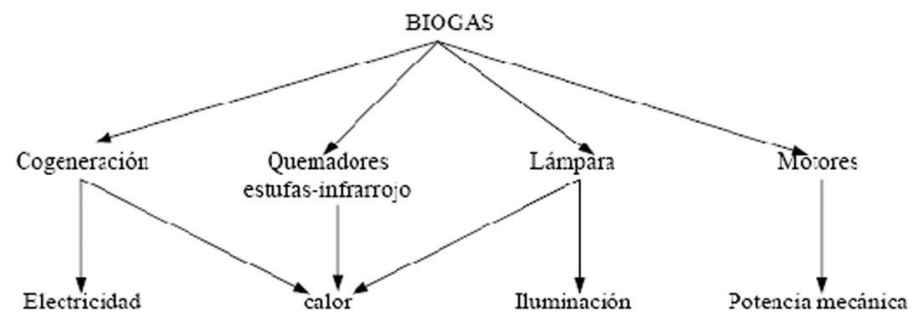

Como se puede observar en el Grafico No 23 existe gran cantidad de formas de utilización del biogás, este dependerá de las necesidades de la empresa y la cantidad de biogás producido en el sistema. El biogás en cada uno de los usos que se le pueda dar tienen un rendimiento especifico (ver grafico 24). En el proyecto se midió en base a horas llama para la cocción de alimentos y en el funcionamiento de un generador de electricidad a gas de 5000 watts y su rendimiento. 


\section{Cuadro No 8}

Consumo y rendimiento de Biogás en diferentes artefactos

\begin{tabular}{|l|c|c|}
\hline \multicolumn{1}{|c|}{ Artefacto } & Consumo & Rendimiento \\
\hline Quemador de cocina & 300 a $600 \mathrm{I} / \mathrm{h}$ & 50 a 60 \\
\hline Lámpara a mantilla (60W) & 120 a $170 \mathrm{I} / \mathrm{h}$ & 30 a 50 \\
\hline Heladera de $100 \mathrm{~L}$ & 30 a $75 \mathrm{I} / \mathrm{h}$ & 20 a 30 \\
\hline Motor a gas & $0,5 \mathrm{m3} / \mathrm{kWh}$ o Hph & 25 a 30 \\
\hline Quemador de $10 \mathrm{~kW}$ & $2 \mathrm{m3} / \mathrm{h}$ & 80 a 90 \\
\hline Infrarrojo de $200 \mathrm{~W}$ & $30 \mathrm{I} / \mathrm{h}$ & 95 a 99 \\
\hline
\end{tabular}

Fuente: INTA, CIPAV, EARTH.

En el Cuadro No 8 se observa los rendimientos del biogás en el funcionamiento de diferentes artefactos útiles en la producción agropecuaria. Existe la necesidad de futuras investigaciones para probar con diferentes artefactos para verificar los enunciados por la literatura en nuestro medio. Cabe señalar que los rendimientos están relacionados también con el tipo de artefacto a utilizar y la buena transformación que se le pueda realizar para el aprovechamiento del biogás.

\section{Grafico No 24}

Rendimiento de un $\mathrm{m}^{3}$ de biogás en diferentes artefactos

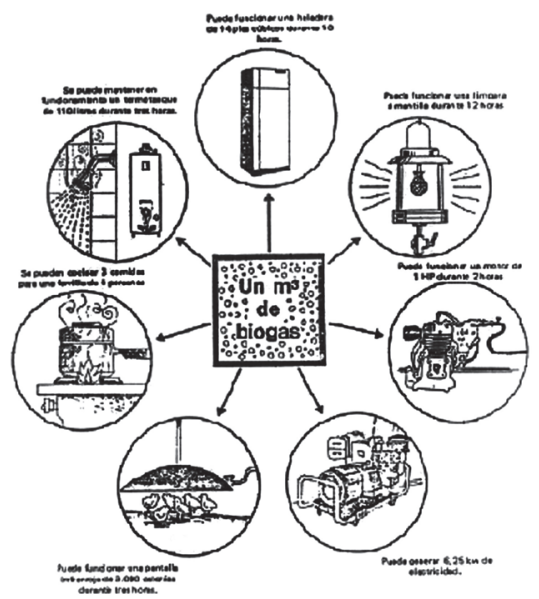

\section{- Producción de horas llama}

Como se puede observar en el Cuadro No 9 no existen diferencias en el tiempo de horas llama de los diferentes tratamientos lo que se puede deber a que la calidad de biogás es la misma de los diferentes tratamientos, lamentablemente no se encontró un sitio donde se pueda enviar a realizar los análisis del gas por lo que se toma de referencia los datos de la literatura (Cuadro 6.). Los biodigestores de la finca OASIS tienen una producción excesiva de biogás si su uso fuera exclusivamente para la cocción de los alimentos de las dos casas de la propiedad por lo que es necesario darle otro uso al biogás.

\section{Cuadro No 9}

\section{Cantidad de horas llama en un quemador por m3 de biogás}

\begin{tabular}{|l|c|c|c|}
\hline Quemador industrial & Estiércol bovino & Estiércol porcino & Estiércol mixto \\
\hline Horas/m3 biogás & 3 & 2,9 & 3 \\
\hline
\end{tabular}

La cantidad de horas llama se realizó con un quemador de tipo industrial a toda potencia con la ayuda de un compresor con la finalidad de equiparar la presión y caudal del gas para los diferentes tratamientos. En el gráfico 25 y 26 se puede observar la diferencia entre la presión con y sin compresor. Esto se debe a que la conexión de la tubería para el funcionamiento del quemador industrial se encuentra a más de 20 m de distancia lo que ocasionó que la presión del gas se reduzca y exista la necesidad de utilizar el compresor.

\section{Grafico No 25}

\section{Quemador sin compresor}

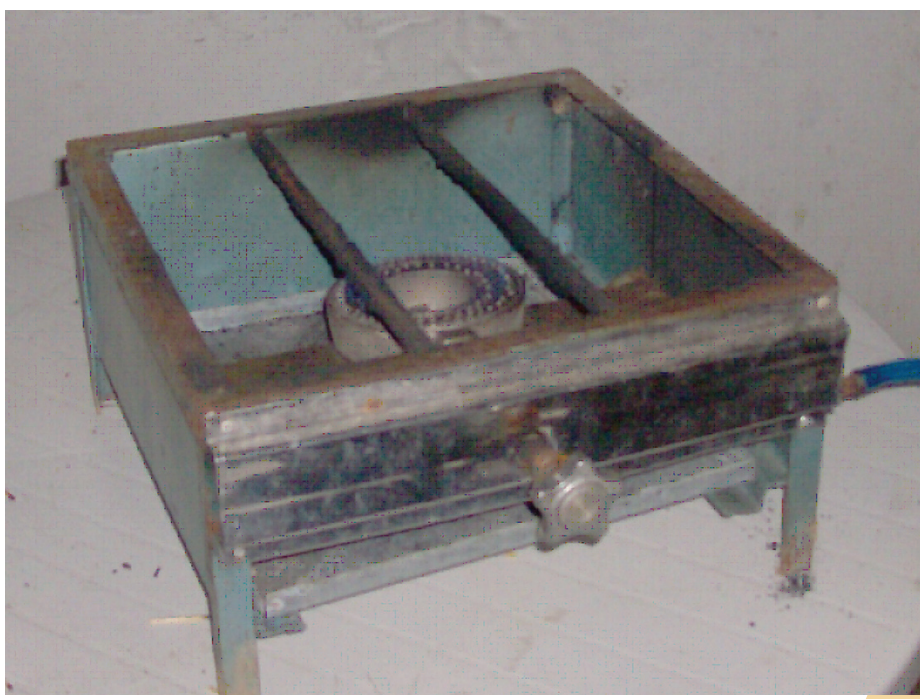




\section{Grafico No 26}

\section{Quemador con compresor}

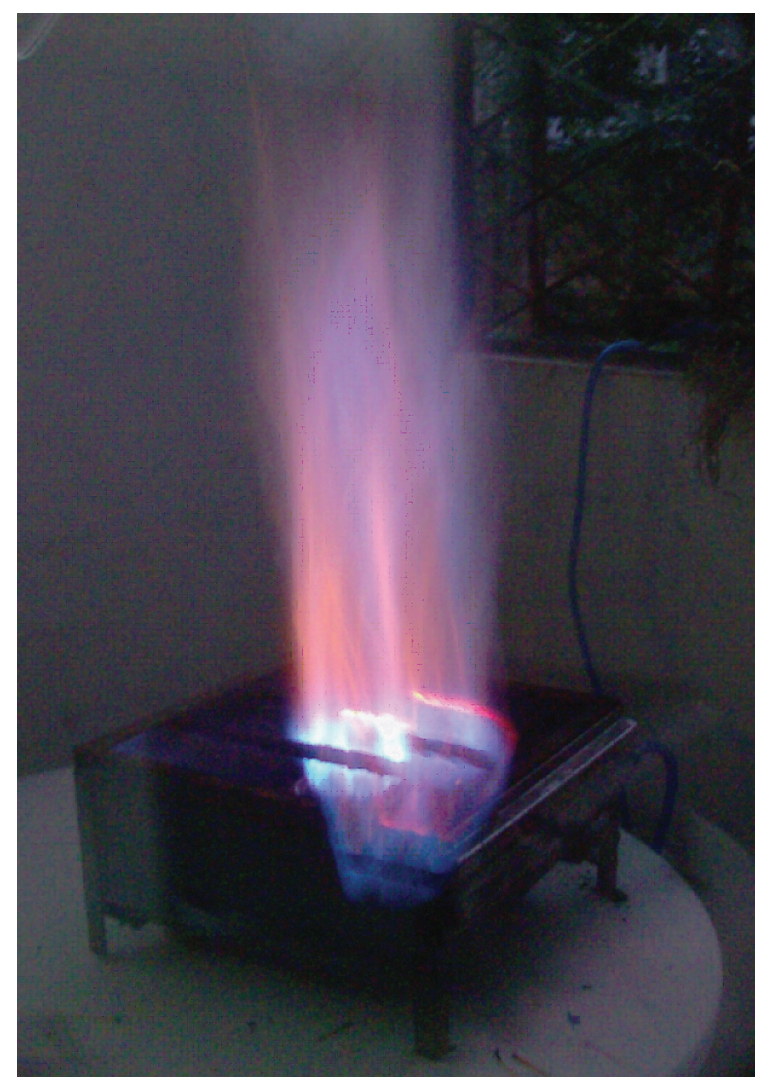

- Producción de energía eléctrica

Para la producción de energía eléctrica se calculó el consumo de la finca y se comparó con los generadores a gas que se encontraban en el mercado, encontrándose el motor HONDA 5000 LPG-B a gas como el que cumplía las características necesarias para la generación de electricidad en la Finca.

\section{- Encendido del motor}

Se intentó en varias ocasiones encender el motor con el biogás lo cual nunca sucedió por sus características propias. Debido a esto se optó el encendido a gas comercial o butano.

\section{- Funcionamiento del motor}

Como se puede observar en el Cuadro No 10 el generador de electricidad a gas no funcionó en su totalidad con el biogás lo que si sucedió con el gas de uso doméstico, posiblemente debido a la calidad del gas emitido por el biodigestor. El motor se encendió con gas domestico (butano) para luego realizar el traspaso por medio de un bypass a biogás; este paso en algunos momentos se dio sin ninguna dificultad y en otros el motor se apagaba para lo cual se realizó varios trabajos con presión y caudal del biogás. En varias ocasiones este paso de biogás se dio sin ninguna dificultad existiendo un buen funcionamiento del motor. Se realizaron varias mediciones con diferentes cargas de voltaje para observar la resistencia del motor con el biogás, solo fue positivo al utilizar focos y los reflectores con un amperaje menor a 2,5 amperios lo que indica que la calidad del gas no abastece el funcionamiento del motor.

\section{Cuadro No 10}

\section{Funcionamiento del motor con diferentes cargas}

\begin{tabular}{|l|c|c|c|c|c|c|c|}
\hline & Encendido & $\begin{array}{c}\text { Funcionamiento } \\
\text { sin carga }\end{array}$ & Focos & Reflectores & $\begin{array}{l}\text { Bomba } \\
\text { 1HP }\end{array}$ & $\begin{array}{l}\text { Bomba } \\
\text { 2 HP }\end{array}$ & Todo \\
\hline Amperaje & & & 0,5 & 2,4 & 17 & 24 & 26 \\
\hline Gas & $\mathrm{Si}$ & $\mathrm{Si}$ & $\mathrm{Si}$ & $\mathrm{Si}$ & $\mathrm{Si}$ & $\mathrm{Si}$ & $\mathrm{Si}$ \\
\hline Biogás & $\mathrm{No}$ & $\mathrm{Si}$ & $\mathrm{Si}$ & $\mathrm{Si}$ & $\mathrm{No}$ & $\mathrm{No}$ & $\mathrm{No}$ \\
\hline
\end{tabular}

Se recomienda seguir investigando en la mejora del sistema de funcionamiento y cambio a biogás con reguladores de presión y sobre todo con nuevos filtros que mejoren la calidad del gas. Se encontró en la literatura que en la Universidad EARTH se pasa el biogás por filtros de óxido de calcio en agua para evitar el monóxido, dióxido de carbono y el ácido sulfhídrico para lo cual se necesita de más tiempo para su implementación y comprobación.

Botero señala que un sistema similar tiene un costo de sesenta mil dólares con un motor a biogás para generar 40 kilovatios/hora, lo que permite mantener encendidos 400 bombillos de 100 vatios, o bien la demanda energética de entre 40 a 60 viviendas dotadas con electrodomésticos básicos. A pesar que la realidad nuestra es diferente los principios son los mismos y se necesita de seguir investigando para llegar a los resultados esperados que las fincas sean autosuficientes en la producción energética y que estos equipos estén al alcance de los 
campesinos ecuatorianos donde la energía aun no llega.

\section{- Efluente}

El proceso fermentativo y de producción de biogás no extrae más que carbono, trazas de azufre, hidrógeno y algo de nitrógeno por reducción de $\mathrm{NH}_{3}$. Para una alimentación media de $50 \mathrm{~kg} /$ día y una producción diaria de $1 \mathrm{~m} 3$ de gas la masa se reducirá solamente en un $2 \%$. La viscosidad del efluente se ve reducida drásticamente debido a la transformación de los sólidos volátiles (un 50\% de los mismos son reducidos en un digestor en régimen). Esto hace al efluente mucho más manejable para su utilización. (INTA, 2005)

El efluente carece prácticamente de olor debido a que las sustancias provocadoras del mal olor son reducidas casi en su totalidad en función al tiempo. La relación Carbono/Nitrógeno se ve reducida mejorando en forma general el efecto fertilizante del efluente.

Los valores de la composición en los principales macro nutrientes por sitio de muestreo y de la literatura se observan en el Cuadro No 9. Se debe tener en cuenta que estos valores son sólo indicativos pues según el tipo de alimentación, raza, manejo, etc.; que tengan los animales y el tratamiento que sufran los estiércoles antes y después de su digestión estos valores pueden variar en forma significativa. Como se puede observar los valores de entrada y salida difieren a los de la literatura posiblemente a lo antes mencionado.

\section{Cuadro No 9}

Cantidad de nutrientes principales por sitio de muestreo y comparación con la literatura

\begin{tabular}{|c|c|c|c|c|c|c|}
\hline Sitio de muestreo & $\% \mathrm{MO}$ & $\% \mathrm{~N}$ & $\% \mathrm{P}$ & $\% \mathrm{~K}$ & $\% \mathrm{Ca}$ & $\% \mathrm{Mg}$ \\
\hline $\begin{array}{l}\text { Entrada } \\
\text { biodigestor } \\
\text { bovino }\end{array}$ & 0,22 & 0,011 & 0,063 & 0,030 & 0,014 & 0,010 \\
\hline 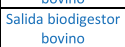 & 0,180 & 0,001 & 0,012 & 0,020 & 0,013 & 0,006 \\
\hline $\begin{array}{c}\text { Entrada } \\
\text { biodigestor } \\
\text { porcino }\end{array}$ & 0,270 & 0,068 & 0,070 & 0,031 & 0,013 & 0,007 \\
\hline \begin{tabular}{|c|}
$\begin{array}{c}\text { Salida biodigestor } \\
\text { porcino }\end{array}$ \\
\end{tabular} & 0,310 & 0,170 & 0,030 & 0,010 & 0,021 & 0,004 \\
\hline $\begin{array}{c}\text { Entrada } \\
\text { biodigestor mixto }\end{array}$ & 0,030 & 0,080 & 0,061 & 0,028 & 0,015 & 0,008 \\
\hline $\begin{array}{c}\begin{array}{c}\text { Salida biodigestor } \\
\text { mixto }\end{array} \\
\end{array}$ & 0,022 & 0,062 & 0,019 & 0,014 & 0,021 & 0,005 \\
\hline $\mathrm{BIOL}+$ & 8,310 & 0,140 & 0,030 & 0,360 & 0,230 & 0,080 \\
\hline 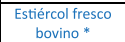 & - & $2,0-0,08$ & $0,6-0,2$ & 1,700 & - & - \\
\hline \begin{tabular}{|l}
$\begin{array}{c}\text { Estiércol digerido } \\
\text { bovino ** }\end{array}$ \\
bovino
\end{tabular} & - & $2,6-0,10$ & $1,4-0,2$ & 1,000 & - & - \\
\hline
\end{tabular}

Debido a su rápida descomposición el efluente brinda rápidamente nutrientes disponibles. Los ácidos húmicos presentes en este material contribuyen a mejorar la estructura del suelo y su porosidad aumentando al mismo tiempo la capacidad de intercambio. La cantidad de humus estable duplica generalmente al que se consigue mediante la utilización de estiércoles incrementando al mismo tiempo en forma significativa la actividad biológica del suelo. (INTA 2005)

El elevado contenido de nitrógeno en forma de amonio $\left(\mathrm{NH}_{4}\right)$ presente en los efluentes ayuda a evitar la pérdida por lavado y lixiviación del nitrógeno del suelo al igual que las pérdidas por volatilización producidas por los procesos de de nitrificación biológica.

Existen amplias evidencias del incremento en la producción de distintas especies vegetales provocada por la aplicación de efluentes al suelo. Tanto en este aspecto como en los anteriores, las aseveraciones y cifras son relativas debido a que se está trabajando con sistemas biológicos muy complejos como son: el material orgánico de carga, el digestor, el suelo y finalmente el cultivo.

Esta interacción y variación provoca grandes diferencias en los resultados y hace difícil cuantificar los beneficios obtenibles de la aplicación así como también definir dosis y modos de aplicación. Es por lo cual se sugiere la utilización del efluente para regar en cultivos con una debida investigación en el tiempo de aplicación, con análisis de suelo para evitar cualquier acumulación tóxica de nutrientes.

\section{Conclusiones y Recomendaciones}

\section{Conclusiones}

1. Se aprovechó la generación de estiércol de la finca EL OASIS utilizando para la producción de biogás y humus de lombriz.

2. La producción de biogás fue ligeramente superior en el estiércol porcino no existiendo diferencias significativas entre los tratamientos por lo cual se puede utilizar independientemente 
cualquier tipo de estiércol para la producción de biogas.

3. El efluente del biodigestor cumple con los parámetros de la legislación ecuatoriana de efluentes para alcantarillas o cuerpos de agua dulce lo cual garantiza que este sistema anaeróbico funciona en la descontaminación de estiércoles.

4. La temperatura influye significativamente en la producción de biogás, existe una relación directamente proporcional a mayor temperatura mayor producción de biogás.

5. No existen diferencias en el tiempo de horas llama de los diferentes tratamientos lo que se puede deber a que la calidad de biogás es la misma de los diferentes tratamientos, existiendo exceso de gas si el consumo fuera solo para la cocción de alimentos.

6. El funcionamiento adecuado del motor generador de electricidad $(5000 \mathrm{~W})$ se dió con el gas comercial butano abasteciendo a toda la necesidad de la finca de 25 amperios, mientras que con el biogás su funcionamiento fue insuficiente solo funcionando para el consumo de 2,4 amperios.

7. La cantidad de nutrientes del efluente es suficiente como para su utilización como abono orgánico en los cultivos y pasturas de la finca para lo cual tiene que investigar para evitar el exceso y por ende la toxicidad.

8. Los biodigestores ayudan a los sistemas de producción ganaderos a descontaminar sus aguas residuales, generación de gas para producción de energía y a producir un abono para los cultivos o pasturas.

\section{Recomendaciones}

1. Se recomiendan los biodigestores para la descontaminación de aguas residuales de la ganadería tropical y como resultado la producción de gas para varios usos y abono orgánico de buena calidad.

2. Es recomendable realizar futuras investigaciones para mejorar la calidad del biogás para generación de energía eléctrica, mejorar la eficiencia de producción y búsqueda de otros usos en la producción animal tropical.

\section{Bibliografía consultada}

1. Aldana L. 2008. Suplementación de Biodigestores con vinaza y su efecto sobre la producción y calidad del biogás y sus efluentes. Universidad EARTH. Costa Rica. 55 p.

2. Amador M.; Castro J. 2008. Relación: Calentamiento global y agricultura orgánica. CEDECO, AGRICULTURA ORGÁNICA 37p.

3. BIOGAS NORD. 2007. Su futuro con el BIOGAS. España. 12 p.

4. Botero R.; Preston T. 1996. Biodigestor Plástico de flujo continuo, generador de gas y bioabono a partir de aguas servida. FAO, CIPAV. Colombia. 22 p.

5. Botero R.; Aguilar F.; Preston T. 2000. El Biodigestor:, Tecnología sencilla y amigable con el ambiente, al alcance de todos. Universidad EARTH. Costa Rica. 28 p.

6. Coto J.; Maldonado J. 2005. Implementación de un sistema para generar electricidad a partir de biogás en EARTH. Universidad EARTH. Costa Rica. 77 p.

7. Miyashiro G. Meggs J. 2007. Medición del efecto de la aplicación de microorganismos eficientes (EM) en la generación de gas metano $\left(\mathrm{CH}_{4}\right)$ en los sistemas biodigestores a escala.

8. Márquez F. 2008. Biogás, su aprovechamiento y generación de electricidad. $27 \mathrm{p}$. 
9. Martínez P.; Servian P. 2007. Evaluación del tratamiento anaeróbico de aguas residuales ordinarias (excretas humanas) de la Universidad EARTH para su aprovechamiento energético. Universidad EARTH. Costa Rica. 74 p.

10. FAO. 2008. La granja y los bosques contra el cambio climático, los países de desarrollo necesitan incentivos. Roma. 2 p.

11. FAO. 2008. Respuesta de la FAO ante el cambio climático. Roma. 2 p.

12. Gobierno de Ecuador. 2002. Norma de Calidad ambiental y de descarga de efluentes: Recurso agua. Ecuador. 35 p.

13. Gobierno de Ecuador. 1976. Ley de prevención y control de contaminación ambiental. 3 p.

14. Hilbert J. 2005. Manual para la producción de Biogás. Instituto Nacional de Tecnología Agropecuaria, INTA. Argentina. 57 p.

15. Martínez H.; Víquez J. 2007. Evaluación de la sostenibilidad de la biogeneración de electricidad por medio del sistema de fermentación anaeróbica, en una combinación de dos biodigestores tipo TAIWAN, alimentados con excretas porcinas y bovinas. Universidad EARTH. Costa Rica. 82 p.

16. Quesada R. et al. 2007. Producción de energía eléctrica a partir de biogás. Universidad EARTH. 9 p.

17. Quesada M.; Salas N. 2006. Generación de energía eléctrica a partir de biogás. Universidad EARTH. Costa Rica. 59 p.

18. Recalde P.; Araya J. 2006. DISEÑO DE TECNOLOGÍAS PARA LA DESCONTAMINACIÓN DE AGUAS RESIDUALES EN SISTEMAS AGROPECUARIOS. Universidad EARTH. Costa Rica. 50 p.

19. Ruiz A. 2002. Calidad de aguas servidas del Sistema de descontaminación en la finca pecuaria integrada de la Universidad EARTH. Universidad EARTH. Costa Rica. $60 \mathrm{p}$
20. Terán P.; Cedeño J. 2007. Evaluación de tres concentraciones de biol en dos frecuencias de aplicación en el cultivo de frejol (Phaseolus vulgaris L.) Santo Domingo 2005. Universidad Tecnológica Equinoccial. Santo Domingo. 112 p.

\section{El Investigador}

José Luis Cedeño Zambrano jcedenio@ute.edu.ec
Ingeniero Agrónomo; Universidad EARTH - Costa Rica, 2003
Maestría en Producción Animal Tropical, Universidad Tecnológica Equinoccial 